\title{
The Effects of Brain Tumours upon Medical Decision-Making Capacity
}

\author{
Will Hewins $^{1,2} \cdot$ Karolis Zienius $^{1} \cdot$ James L. Rogers ${ }^{3} \cdot$ Simon Kerrigan $^{4} \cdot$ Mark Bernstein $^{5} \cdot$ Robin Grant $^{1,2}$
}

Published online: 2 May 2019

(C) The Author(s) 2019

\begin{abstract}
Purpose of Review Informed consent is the integral part of good medical practice in patients with brain tumours. Capacity to consent may be affected by the brain disorder or its treatment. We intend to draw upon the current neuro-oncology literature to discuss the influence intracranial tumours have upon patients' capacity to consent to treatment and research.

Recent Findings We performed a systematic review of studies of capacity to consent for treatment or research in patients with intracranial tumours. The search retrieved 1597 papers of which 8 were considered eligible for review.

Summary Although there are obvious inherent limitations to solely assessing cognition, most research consistently demonstrated increased risk of incapacity in brain tumour patients with cognitive impairment. Specific items in cognitive screening batteries, for example Semantic Verbal Fluency Test (SVFT), Hopkins Verbal Learning Test (HVLT-Recall), and Trail Making Test A/B (TMT), are simple, easily applied tests that may act as significant red flags to identify patients at increased risk of incapacity and who subsequently will require additional cognitive/psychiatric evaluation or more formal tests for capacity to consent for treatment or research.
\end{abstract}

Keywords Brain tumour $\cdot$ Capacity $\cdot$ Shared decision-making $\cdot$ Legal consent $\cdot$ Glioma $\cdot$ Brain metastasis

\section{Introduction}

Before surgical treatment can take place, informed consent must be obtained from the adult patient. Informed consent requires that the patient be an adult and that they receive all relevant information, in an appropriate format, to enable the patient to understand, remember, evaluate, and communicate their decision. The patient must possess the prerequisite mental capacity to come to an autonomous and informed decision about their care. All adults are assumed to possess the mental

This article is part of the Topical Collection on Neuro-oncology

\section{Robin Grant}

robin.grant@nhslothian.scot.nhs.uk

Will Hewins

whewins@exseed.ed.ac.uk; WHewins@ed.ac.uk

Karolis Zienius

zienius.k@gmail.com

James L. Rogers

jroger2@tulane.edu

Simon Kerrigan

Simon.Kerrigan@srft.nhs.uk capacity to make medical decisions about their care. Only at the point an individual demonstrates a deficit in cognition or disturbed mental state should assessment of their mental capacity be initiated. At this point, it is the treating physician's duty of care to identify and attempt to accommodate the patient's ability to understand and retain the relevant information long enough for them to weigh-up and communicate their decision. The effects of any underlying condition or side effects of prior treatment must also be considered. A myriad of complications from infection to general confusion can cause

Mark Bernstein

mark.bernstein@uhn.ca

1 Department of Clinical Neurosciences, Western General Hospital, Edinburgh EH4 2XU, Scotland

2 Centre for Clinical Brain Sciences, University of Edinburgh, Edinburgh EH16 4SB, UK

3 Tulane University, New Orleans, LA, USA

4 Department of Neurology, Salford Royal NHS Foundation Trust, Stott Lane, Salford M6 8HD, UK

5 Division of Neurosurgery, Toronto Western Hospital, University of Toronto, Toronto, Canada 
temporary loss of capacity. In cases where it is possible to wait for these factors to be treated or overcome, such steps should be taken before obtaining legal consent for surgical procedures. After all appropriate support has been exhausted, if the patient still cannot make a reasoned decision regarding the procedure, the patient is considered to have incapacity. The assessment of incapacity must always remain specific to both the patient and their given treatment decision. Judgement of incapacity can change throughout a patient's illness and should be seen as a continually evolving set of constructs (see Mental Capacity Act, 2005 [1]) that may affect medical decision-making.

Whilst capacity must be assessed on a case-by-case basis, certain risk factors [2, 3] and medical conditions are associated with an increased likelihood of incapacity $[4,5]$. The largest body of literature comes from neurodegenerative and psychiatric conditions [6-8], in which disturbance of thought or cognition is often noted alongside incapacity [9]. Patients with intra-cerebral tumours often present with cognitive impairment from the tumour itself or treatment side effects [10] and are at a high risk of having incapacity [11].

We have performed a systematic review of studies of capacity to consent for treatment or research in patients with brain tumours.

\section{Methods}

\section{Literature Searches}

A preliminary scoping search (Appendix 1) was conducted to classify study identifiers to be used in the full systematic review. The scoping search drew 1133 research articles which were screened by a researcher. The findings from this search were only used in identifying appropriate parameters for a detailed literature search and no data were extracted.

The full literature search strategy (Appendix 2) was developed in conjunction with an information specialist at Cochrane Neuro-Oncology. The full Embase directory was used when applying the search strategy yielding 1596 results.

\section{Study Eligibility}

After removal of duplicate articles, titles and abstracts of 1586 research articles were initially screened for immediate inclusion criteria. Due to the relatively limited findings of the scoping search, only two standards were used to identify papers suited for further assessment: (1) patient population were adults aged 16 years or older who were diagnosed with a central nervous system tumour and (2) capacity to consent to either research or medical treatment as an outcome measure. Twenty-seven research articles were identified as eligible for full-text assessment. Upon full-text assessment, 19 of these papers were deemed ineligible (see Fig. 1). Eight full-text articles were included in the present review. A brief summary of the six studies we extracted data from is shown in Table 1 . Due to the limited results and variance in methodologies utilised by researchers, quantitative analyses were not performed.

\section{The Assessment of Mental Capacity}

Whilst there is not yet a gold-standard assessment of capacity, several tools exist to aid assessment [13-15]. Three such assessments are the MacArthur Competence Assessment Tool for Treatment (MacCAT-T), Competency to Consent to Treatment Instrument (CCTI), and the Competency to Consent to Research Instrument (CCRI). The MacCAT-T offers clinicians a semi-structured interview process to ensure all facets of capacity are discussed and appraised before assessment is made. The MacCAT-T utilises the real-world proposed treatment option with the patient and has seen good clinical utility in general inpatient, psychiatric, and end-of-life cancer populations $[2,6,16]$. The CCTI and CCRI on the other hand offer hypothetical treatment or research vignettes to which a patient is assessed on their performance across the four constructs of capacity (understanding, appreciation, reasoning, and expression of choice). Whilst the instruments have seen utility across a range of populations [17, 18] and all three assessments are deemed substantially more robust than clinician appraisal alone, they all still rely on the clinician's subjective appraisal of information portrayed by the patient.

\section{Cognitive Assessment}

Theorised cognitive underpinnings of capacity $[19,20]$ have been compared to standardised cognitive batteries in an attempt to simplify and standardise the binary decision whether a patient has or does not have capacity to make a decision around a specific treatment, such as, surgery [21]. Immediate limitations to using such methods revolve around the duration of administering detailed neuropsychological assessments. Instead of in-depth, and often arduous neuropsychological assessments, abbreviated cognitive batteries have been considered as potential stand-ins for capacity assessment [22, 23]. The poor sensitivity of the Mini-Mental State Examination (MMSE) alone limits its use as a formal capacity assessment [24]. Further, the MMSE lacks sensitivity to executive functions [25, 26], a domain regularly shown to be important when assessing decision-making and mental capacity [27, 28].

Updated approaches to the rapid assessment of cognitive status such as the Addenbrooke's Cognitive Examination (ACE) and the Montreal Cognitive Assessment (MoCA) are both considered more sensitive than the MMSE and, amongst other shared neurocognitive subtests, both include 
Fig. 1 Adapted PRISMA flow diagram [12]

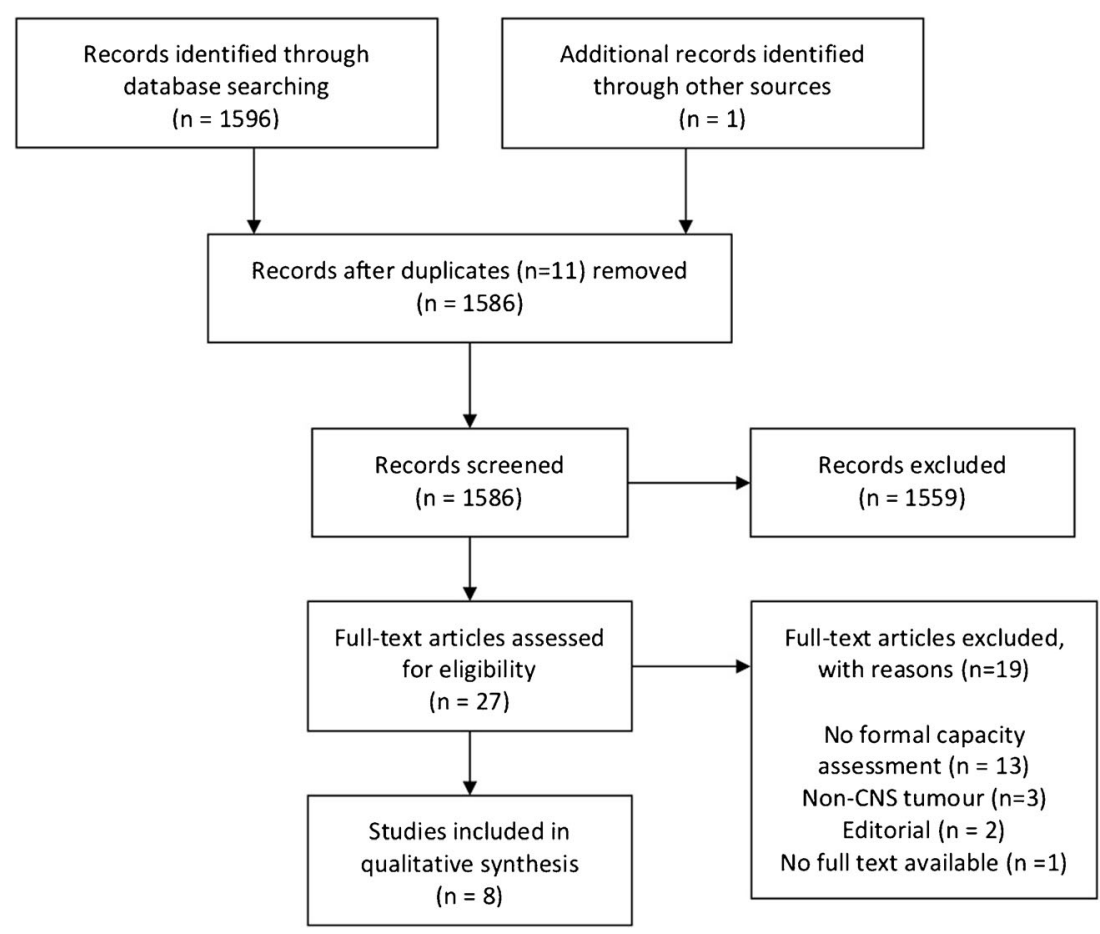

brief assessment of executive function. Importantly, the ACE has been demonstrated as a sensitive test for patients with brain tumour, when screening for capacity to give consent prior to surgery compared with the MacCAT-T, performed by a dual-trained lawyer and neurologist [29]. In this study, investigating capacity in suspected intracranial tumour patients found that $25 \%$ of patients were found to lack the mental capacity required to consent to their neurosurgical treatment. Of particular note, the authors report poor performance on the semantic verbal fluency subtest (SVFT- how many animals can you think of in a minute') to predict incapacity with $96 \%$ sensitivity and $63 \%$ specificity. The addition of a brief cognitive test involving the recall of a 7 -item name and address after three attempts to memorise it increased the sensitivity to $100 \%$, specificity $83 \%$, and $66 \%$ positive predictive value compared with the MacCAT-T. These subtests, however, should not be seen as a proxy for capacity assessment $[22,29]$. Rather, poor performance on cognitive assessment should be considered as a 'red flag', mandating a more rigorous capacity assessment.

\section{Mental Capacity in Brain Tumour}

The systematic review identified two case control studies assessing capacity in known primary brain tumour (PBT) patients following surgery. Patients and controls were consented, and capacity was assessed using a hypothetical scenario for treatment. Triebel and colleagues [18] found that compared to controls, PBT patients were impaired using the CCTI capacity constructs of reasoning and understanding (35\% and 54\%, respectively) and $23 \%$ of patients had a compromised construct of appreciation that approached statistical significance $(p=0.06)$. Cognitive performance in tests of verbal memory, semantic fluency, and executive function showed strongest associations with appreciation. Multivariate analysis indicated around half of appreciation performance variance was attributable to Hopkins Verbal Learning Test (HVLT) recognition discrimination index and animal word fluency test performance. Both reasoning and understanding showed strongest associations with verbal acquisition and recall (HVLT total), semantic fluency (animal word fluency), and executive function (Trail Making Test B). Multivariate analysis indicated Total HVLT performance to account for $33 \%$ of patient variance in reasoning, whereas combined HVLT total and animal word fluency performance accounted for $72 \%$ of the variance in understanding scores.

When assessing research consent capacity using the CCRI, understanding appeared once again most commonly impaired [30]. Unlike treatment consent, more patients were impaired in appreciation than reasoning ( $31 \%$ and $23 \%$, respectively). Multivariate analyses suggested semantic word fluency as the sole predictor for the appreciation standard of the CCRI, accounting for $61 \%$ of its variance. Phonemic fluency accounted for $30 \%$ variance in reasoning performance and both phonemic fluency and semantic fluency emerged as the two-step multivariate predictors of understanding, accounting for $71 \%$ of the variance. Again, no such associations were drawn between any cognitive performance and the consent facet of expressing a choice. 
Table 1 A brief description of studies and their main findings used in the present review

\begin{tabular}{|c|c|c|c|c|c|c|}
\hline Study & Diagnosis & $\begin{array}{l}\text { Number } \\
\text { of } \\
\text { patients }\end{array}$ & Control & $\begin{array}{l}\text { Capacity } \\
\text { assessment }\end{array}$ & $\begin{array}{l}\text { Test timepoint } \\
\text { (consent) }\end{array}$ & Main findings \\
\hline $\begin{array}{l}\text { Triebel } \\
\text { et al. [18] }\end{array}$ & Malignant glioma & 26 & Yes & CCTI & $\begin{array}{l}\text { Average time from } \\
\text { diagnosis }=6.9 \\
\text { months }\end{array}$ & $\begin{array}{l}\text { Over } 50 \% \text { of patients showed compromised } \\
\text { capacity in medical decision-making. } \\
\text { Cognitive performance on verbal acquisition } \\
\text { and recall, in addition to semantic fluency, } \\
\text { predicted performance of the appreciation, } \\
\text { reasoning, and understanding } \\
\text { standards of consent. }\end{array}$ \\
\hline $\begin{array}{l}\text { Marson } \\
\quad \text { et al. [30] }\end{array}$ & Malignant glioma & 26 & Yes & CCRI & $\begin{array}{l}\text { Average time from } \\
\text { diagnosis }=6.9 \\
\text { months }\end{array}$ & $\begin{array}{l}\text { Malignant glioma patients performed significantly } \\
\text { below the controls on the consent standards of } \\
\text { appreciation, reasoning, and understanding. } \\
\text { Around one-third of patients showed } \\
\text { compromised capacity. Phonemic and semantic } \\
\text { verbal fluency found to predict CCRI } \\
\text { performance. }\end{array}$ \\
\hline $\begin{array}{l}\text { Kerrigan } \\
\text { et al. [29] }\end{array}$ & $\begin{array}{l}\text { Radiologically } \\
\text { suspected } \\
\text { intracranial tumour }\end{array}$ & 100 & No & MacCAT-T & $\begin{array}{l}\text { Preoperative } \\
\text { (no consent } \\
\text { required) }\end{array}$ & $\begin{array}{l}25 \% \text { of patients lacked mental capacity to give } \\
\text { valid consent to neurosurgery, of which almost } \\
\text { half were missed on initial capacity assessment } \\
\text { by the neurosurgical team. Patients lacking } \\
\text { mental capacity were significantly more } \\
\text { cognitively impaired than those with capacity. } \\
\text { ACE-R semantic verbal fluency performance } \\
\text { and ability to repeat } 7 \text {-item name and address } \\
\text { after three attempts were predictive of } \\
\text { incapacity. }\end{array}$ \\
\hline $\begin{array}{l}\text { Gerstenecker } \\
\text { et al. }[31 \bullet \bullet]\end{array}$ & Brain metastasis & 41 & Yes & CCTI & $\begin{array}{l}\text { Within a week } \\
\text { before starting RT }\end{array}$ & $\begin{array}{l}\text { The understanding facet of capacity was } \\
\text { associated with a range of cognitive } \\
\text { performances. Also, performance in phonemic } \\
\text { fluency and verbal memory were found to be } \\
\text { predictors of capacity to understand a treatment } \\
\text { decision. }\end{array}$ \\
\hline $\begin{array}{l}\text { Gerstenecker } \\
\text { et al. [32••] }\end{array}$ & Brain metastasis & 41 & Yes & CCTI & $\begin{array}{l}\text { Within a week } \\
\text { before starting RT }\end{array}$ & $\begin{array}{l}\text { The reasoning facet of capacity shared significant } \\
\text { associations with two cognitive performance } \\
\text { aspects. Also, episodic memory and processing } \\
\text { speed performance were found to be predictive } \\
\text { of capacity to reason through a treatment } \\
\text { decision. }\end{array}$ \\
\hline
\end{tabular}

*Patients with a diagnosis of either a primary or metastatic brain tumour were included in the study

Requirements - direct assessment of capacity using either MACCAT-T or CCTR/CCRI

$A C E-R$, Addenbrooke's Cognitive Examination-revised; $C C R I$, Capacity to Consent to Research Instrument; CCTI, Capacity to Consent to Treatment Instrument; KPS, Karnofsky Performance Scale; MACCAT-T, MacArthur Competence Assessment Tool for Treatment

There are clear similarities between the two studies investigating primary brain tumours and capacity $[18,30]$. Much like the aforementioned findings of Kerrigan [29] where semantic verbal fluency score $\leq 10$ words in a minute was associated with lack of capacity to consent for surgery, verbal memory and verbal fluency offered potential 'red flags' whereby poor performance could indicate the need to further assess capacity.

Three further studies were identified reporting on capacity

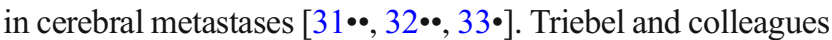
report $61 \%$ of all patients diagnosed with brain metastases showed some form of deficit in capacity $(<1.5$ SD below the mean in one construct area) when assessed within a week of starting radiotherapy for their brain metastases [33•]. Only one patient showed impaired expression of treatment choice, with a further $17 \%$ of patients showing impairment in appreciation, $39 \%$ in reasoning, and $46 \%$ of patients showing some form of impairment in their ability to understand treatment decisions. This apparent rank order of incidence likely relates to the order of complexity each facet assesses [34, 35]. Significant differences between control and patient performance were only reported in reasoning and understanding.

In the pair of papers presented by Gerstenecker and colleagues, 41 patients with diagnosed brain metastases were compared against demographically matched controls for cognitive predictors of understanding [31••] and reasoning 
through $[32 \bullet \cdot]$ treatment decisions. Forty-six percent of patients were found to have impaired understanding, as defined by a score of $\geq 1.5$ standard deviation below control group average performance. By the same definition, 39\% of patients were found to present impaired decision-making capacity in reasoning through a treatment decision. The capacity construct of reasoning was also significantly associated with cognitive performance in verbal memory and processing speed. As such, the researchers were able to report an equation to predict the likelihood of a patient presenting with impaired or intact reasoning capacity utilising test scores on both HVLT Delayed Recall and Trail Making Test A [32••]. Similar associations were also reported in Gerstenecker et al.'s paper investigating the capacity construct of understanding $[31 \bullet \cdot$. As was seen in the reasoning construct, both delayed recall and trail making tests were significantly associated with understanding. In addition to these, several other cognitive performances were found significant (see Table 2). Of note, performance in phonemic fluency and HVLT total score allowed logistic regression predictions to impaired or intact understanding to be performed.

\section{The Effect of Tumour and Patient Profiles}

\section{Tumour Location}

No studies identified in the present literature review specifically investigated the effects of tumour location on capacity. There is, however, an opportunity to draw indirect associations from a growing body of literature regarding lesion sites and their associated cognitive impairment [36, 37]. Mattavelli and colleagues, for example, report a deficit in cognitive decision-making in frontal low-grade glioma [38]. Whilst pragmatically similar, poor performance in a cognitive decision-making task cannot be translated to poor medical decision-making without formal capacity assessment. Due to theorised higher order cognitive underpinnings of capacity $[20,29,39,40]$, constructs of capacity are unlikely attributable to any one specific neural location nor tumour site. Instead, it is much more conceivable that damage to any number of locations associated with that cognitive function and in turn capacity performance to manifest in impairment.

\section{Tumour Grade}

Patients with low-grade glioma most commonly present with seizures, whilst those with high-grade glioma more commonly present with focal neurological or cognitive deficits and headache associated with raised intracranial pressure. More recently, tumour grade has been considered more important with respect to neurocognitive abilities than tumour volume, seizure status, or concomitant medication in newly diagnosed glioma [41, 42]. Kerrigan and colleagues reported the incidence of incapacity in relation to WHO tumour grade [11, 29]. Lack of capacity to consent was associated with glioblastoma suggesting that the rapid tumour growth may affect neurocognitive performance by limiting the extent neuroplasticity can accommodate lesion-based changes in the brain $[36,43]$. Importantly, cognitive functions found by Noll et al. to be influenced by tumour grade were in line with those associated with capacity, specifically, verbal learning, executive function, and language ability [41]. Such associations specifically in the context of capacity assessment warrant further investigation with the intent of uncovering additional risk factors to the cognitive red flags described earlier.

Table 2 A summary of statistically significant regression analyses as reported in reviewed research

\begin{tabular}{|c|c|c|c|c|c|}
\hline Capacity function & Author (year) & Patient sample & Statistical analysis & Cognitive test & Statistic/significance \\
\hline \multirow[t]{2}{*}{ Appreciation } & Triebel et al. [18] & Malignant glioma & Stepwise regression & $\begin{array}{l}\text { HVLT-RDI } \\
\text { Animal fluency }\end{array}$ & $\begin{array}{l}R^{2}=0.50 * * * \\
R^{2}=0.58^{*}\end{array}$ \\
\hline & Marson et al. [30] & Malignant glioma & Stepwise regression & Animal fluency & $R^{2}=0.62 * * *$ \\
\hline \multirow[t]{3}{*}{ Reasoning } & Triebal et al. [18] & Malignant glioma & Stepwise regression & HVLT trials $1-3$ & $R^{2}=0.36^{* * *}$ \\
\hline & Marson et al. [30] & Malignant glioma & Stepwise regression & Letter fluency & $R^{2}=0.34 * *$ \\
\hline & Gerstenecker et al. [32••] & Brain metastases & Linear regression & HVLT delayed and TMT A & $R^{2}=0.18^{*}$ \\
\hline \multirow[t]{3}{*}{ Understanding } & Triebal et al. [18] & Malignant glioma & Stepwise regression & $\begin{array}{l}\text { HVLT trials } 1-3 \\
\text { Animal fluency } \\
\text { Trial B }\end{array}$ & $\begin{array}{l}R^{2}=0.68 * * * \\
R^{2}=0.75 * \\
r=-0.79 * *\end{array}$ \\
\hline & Marson et al. [30] & Malignant glioma & Stepwise regression & $\begin{array}{l}\text { Letter fluency } \\
\text { Animal fluency }\end{array}$ & $\begin{array}{l}R^{2}=0.64 * * * \\
R^{2}=0.73 * * *\end{array}$ \\
\hline & Gerstenecker et al. [31••] & Brain metastases & Stepwise regression & $\begin{array}{l}\text { HVLT total } \\
\text { HVLT total and phonemic fluency }\end{array}$ & $\begin{array}{l}R^{2}=0.58 * * * \\
R^{2}=0.68 * * *\end{array}$ \\
\hline
\end{tabular}

Significance levels: $* p \leq .05, * * p \leq .01, * * * p \leq .001$

All $R^{2}$ reported are cumulative, not adjusted 


\section{Effects of Treatment}

The effect of surgery on a patient's capacity to consent to subsequent treatments is likely an area of substantial interest due to the potential of side effects and relatively short interlude between follow-up treatments [37]. With respect to subsequent treatments, only one study reported the frequency of incapacity in relation to their treatment $[32 \bullet \cdot]$. No significant differences were seen between radiation and chemotherapy and no correction was made to account for patients who had both treatments. The limited data currently available leave this question open for further study. It is likely that both treatments have at least a transient effect on cognition [44] with the impact and duration of side effects often varying between treatment approaches [45-47], their influence on capacity may also be transient in nature. There are, however, increasing concerns over the persistence of cognitive impairment experienced following whole brain radiation therapy; as such, treatment fields and dose should be considered when making capacity assessment. There is growing evidence that hippocampal avoidance techniques may limit future cognitive impairment [48-50] and such techniques should be considered in reference to treatment influence on capacity.

Only one study reviewed reported on associations between current medication use and mental capacity. Marson et al. (2010) found that corticosteroid use was significantly associated with impaired capacity for appreciation, reasoning, and understanding [30]. Anticonvulsant medication was also associated with reasoning and understanding, although to a lesser extent. From the data presented by Marson and colleagues, it is impossible to say whether this finding is indicative of the drugs themselves or the underlying symptoms the drugs are aimed at combatting. Corticosteroids, for example, are regularly used to treat oedema and its associated neurological symptoms which can often manifest in cognitive disturbance [51, 52]. Anticonvulsants, on the other hand, are prescribed to manage seizures, and side effects can often involve disturbance in personality, cognition, or fatigue [53]; however, the limited findings warrant further investigation.

\section{Effect of Performance Status}

The Karnofsky Performance Scale (KPS) is a scale regularly used in oncology to record the disability of a cancer patient [54]. In a mixed sample of primary and secondary brain tumour patients, Martin and colleagues investigated the relationship between KPS and CCTI performance [55]. Significant differences in performance on scales of appreciation and understanding were noted between patients with KPS scores of 90-100 and 70-80. Almost half of patients with KPS $\geq 90$ and only $23 \%$ of patients with a KPS of $70-80$ scored within normal range in all constructs of the CCTI. The high frequency of scores below 1.5 standard deviations from mean in at least one construct of the CCTI limits the clinical utility of using the KPS as a red flag for incapacity.

\section{Effect of Emotion}

Across all research reviewed, age, gender, time since diagnosis, or depression did not appear to have a significant influence upon capacity. Only one paper suggested years of education and gender to have an association with capacity in brain tumour patients [29]. Mood assessment in all studies was brief and the lack of associations between depressive symptoms and incapacity is perhaps unusual, as depression is often seen to influence the information processing speed [56] and subsequent decision-making [57]. Kerrigan et al. report poor tolerance towards completing the Hospital Anxiety and Depression Scale (HADS), a relatively brief patient-reported outcome measure (PROM) [29]. Sixty-eight percent of patients who were found not to have capacity to consent to surgery using the MacCAT-T assessment were unable to complete the HADS satisfactorily. A further $13 \%$ of patients with capacity were also unable to adequately complete the test. Due to the more inclusive sampling technique used by Kerrigan and colleagues [29], such findings may be more indicative of generalised brain tumour patients' ability to use self-report items than by other researchers in this review and explain the low influence of mood throughout the review findings. Alternatively, it is possible that mood scores were generally low across all patients and no clear association between mood and capacity could be identified. Therefore, assessment of mood should be evaluated in addition to capacity as depression is often considered a concern in regard to a patient's capacity [58].

Suitable, simple, and clear presentation of information during shared decision-making has been proven to reduce anxiety of glioma patients prior to treatment [59]. Although simple plain language explanations should be common practice in modern medicine, a review of information needs in patients of brain tumour reveals otherwise [60]. The present review identified only one study investigating brain tumour patients' capacity to consent to research. Due to the relatively poor outcomes of interventions available to brain tumour patients, the increasing number of clinical trials and more complex trial designs and consent forms, patients may be 'at-risk' of being exploited for their participation [61]. Ibrahim and colleagues report patients being fought over for their participation in clinical research [62], with coercion a possible occurrence of such research [63]. Patients may show a preconceived preference to active treatment over wait-and-see proposals regardless of evidence-based clinician guidance [64]. 
As illustrated by Kerrigan et al. the tolerability of certain PROMs is another element to consider when investigating brain tumour patients, particularly those with impaired capacity [29]. If a relatively brief and simple PROM, such as the HADS, is poorly tolerated in brain tumour patients prior to surgical intervention, more detailed and demanding PROMs are likely also heavily influenced in this population. When a patient is identified as lacking capacity during a study, researchers must make the decision as to whether or not completed PROM data are reliable. As illustrated in the present review, patients lacking capacity have the potential to make up a significant proportion of the patient population and ethically, one must consider whether continued participation in a trial is justified. Patient-proxy or observer-reported outcomes are gaining traction in clinical trials where the reliability of PROMs is brought to question.

\section{Conclusion}

Medical decision-making capacity remains under assessed in neuro-oncology. Many of the studies trying to understand what influences capacity have focused on identifying possible cognitive links. However, cognitive performance cannot be used as a capacity test stand-in. Certain assessments, such as the SVFT, HVLT-R, and TMT A/B, may be useful in 'flagging' patients that may require further neuropsychological assessment. When considering the Kerrigan et al. [29] and Sullivan et al. [21] studies, it is clear that identifying those patients in need of a more detailed assessment is far more beneficial than evaluating all patients in a detailed manner. The use of ROC analysis to infer clinical utility of cognitive test performance in identifying patients who may require further assessment of capacity is more robust than correlation analysis alone. Whilst regression analyses used in Gerstenecker and colleague's research $[31 \bullet \bullet, 32 \bullet \bullet$ offer statistical predictions of incapacity in brain tumour populations, the utility of this in real-world clinical settings may be more limited. The authors propose it is of greater benefit to identify rapid means of assessment than it is to present statistical models to which patient data can be imputed.

Whilst there is limited literature to suggest an influence of tumour type, grade, or location on capacity, there is a recurring theme across numerous studies suggesting tumour characteristics' influences on cognitive abilities such as verbal fluency, memory, and executive function. Likewise, there is a limited literature to suggest any therapeutic or medicinal influences on the longitudinal effects of capacity throughout the treatment process. This is of particular importance in the brain tumour population due to the extent of treatment that is required throughout their disease trajectory. Finally, the effect of emotion on medical decision-making is poorly understood. A clinician's duty of care should remain and serve to offer impartial advice on all treatment and research options available.

\section{Compliance with Ethical Standards}

Conflict of Interest The authors declare they have no conflict of interest.

Human and Animal Rights and Informed Consent This article does not contain any studies with human or animal subjects performed by any of the authors.

\section{Appendix 1. Scoping search strategy}

1. Exp INFORMED CONSENT/

2. Exp Presumed Consent/

3. Exp mental Competency

4. 1 or 2 or 3

5. Neoplasms/ or exp nervous system neoplasms/

6. 4 and 5

\section{Appendix 2. Embase search strategy}

1. exp informed consent/

2. (informed adj2 (consent or decision* or choice*)).tw.

3. informed decision making.tw.

4. informed choice.tw.

5. (consent* adj (process or form* or document*)).tw.

6. consent process.tw.

7. consent*.tw.

8. (improv* adj2 consent).tw.

9. (understanding adj2 consent).tw.

10. presumed consent.mp.

11. exp mental capacity/

12. ((competen* or capacity*) adj5 (consent* or decision* or choice*)).tw.

13. 1 or 2 or 3 or 4 or 5 or 6 or 7 or 8 or 9 or 10 or 11 or 12

14. exp central nervous system tumor/

15. ((central nervous system or CNS or brain* or cerebral* or intracerebral or intra-cerebral or intracranial or intracranial or spine or spinal or astrocytic or oligodendroglial or ependymal) adj5 (cancer* or tumor* or tumour* or malignan* or neoplas* or carcinoma*)).tw.

16. exp neuroepithelioma/

17. ( (glioneural or neuroectodermal or embryonal or neuroepithelial or pineal or choroid plexus or teratoid or rhabdoid) adj5 (tumor* or tumour*)).tw.

18. (glioma* or glial* or astrocytoma* or xanthoastrocytoma* or glioblastoma* or gliosarcoma* or oligodendrogli* or oligoastrocyt* or ependym* or subependym* or astroblastoma* or ganglioglioma* or gangliocytoma* or neurocytoma* or liponeurocytoma* or pineocytoma* or 
pineoblastoma* or medulloblastoma* or neuroblastoma* or ganglioneuroblastoma*or medulloepithelioma* or GBM*).tw.

19. 14 or 15 or 16 or 17 or 18

20. 13 and 19

21. limit 20 to embase

Open Access This article is distributed under the terms of the Creative Commons Attribution 4.0 International License (http:// creativecommons.org/licenses/by/4.0/), which permits unrestricted use, distribution, and reproduction in any medium, provided you give appropriate credit to the original author(s) and the source, provide a link to the Creative Commons license, and indicate if changes were made.

\section{References}

Papers of particular interest, published recently, have been highlighted as:

- Of importance

- Of major importance

1. Mental Capacity Act 2005. https://www.legislation.gov.uk/ukpga/ 2005/9/contents

2. Raymont V, Bingley W, Buchanan A, David AS, Hayward P, Wessely S, et al. Prevalence of mental incapacity in medical inpatients and associated risk factors: cross-sectional study. Lancet. 2004;364:1421-7.

3. Hotopf M. The assessment of mental capacity. Clin Med. 2005;5: 580-4.

4. Lepping P. Overestimating patients' capacity. Br J Psychiatry. 2011;199:355-6.

5. Bernstein M. Under-recognized mental incapacity in brain tumour patients. Neuro-Oncology. 2014;10(9):487.

6. Cairns R, Maddock C, Buchanan A, David AS, Hayward P, Richardson G, et al. Prevalence and predictors of mental incapacity in psychiatric in-patients. Br J Psychiatry. 2005;187:379-85.

7. Owen GS, Richardson G, David AS, Szmukler G, Hayward P, Hotopf M. Mental capacity to make decisions on treatment in people admitted to psychiatric hospitals: cross sectional study. BMJ. 2008;337:a448.

8. Hegde S, Ellajosyula R. Capacity issues and decision-making in dementia. Ann Indian Acad Neurol. 2016;19(1):S34.

9. Moye J, Karel MJ, Gurrera RJ, Azar AR. Neropsychological predictors of decision-making capacity over 9 months in mild-tomoderate dementia. J Gen Intern Med. 2006;21(1):78-83.

10. Boele F, Rooney AG, Grant R, Klein M. Psychiatric symptoms in glioma patients: from diagnosis to management. Neuropsychiatr Dis Treat. 2015;10:1413-20.

11. Kerrigan S, Dengu F, Erridge S, Grant R, Whittle IR. Recognition of mental incapacity when consenting patients with intracranial tumours for surgery: how well are we doing? Br J Neurosurg. 2012;26(1):28-31.

12. Moher D, Liberati A, Tetzlaff J, Altman DG, The PRISMA Group. Preferred reporting items for systematic reviews and meta-analyses: the PRISMA statement. BMJ. 2009;339:b2535.

13. Sturman ED. The capacity to consent to treatment and research: a review of standardized assessment tools. Clin Psychol Rev. 2005;25(7):954-74.
14. Dunn B, Nowrangi PA, Palmer BW, Jest V, Saks ER. Assessing decisional capacity for clinical research or treatment: a review of instruments. Am J Psychiatry. 2004;163:1323-34.

15. Lamont S, Jeon Y-H, Chiarella M. Assessing patient capacity to consent to treatment: an integrative review of instruments and tools. J Clin Nurs. 2013;22(17-18):2387-403.

16. Kolva E, Rosenfeld B, Saracino R. Assessing the decision-making capacity of terminally ill patients with cancer. Am J Geriatr Psychiatry. 2017;26:523-31.

17. Dreer LE, Devivo MJ, Novack TA, Krzywanski S, Marson DC. Cognitive predictors of medical decision-making in traumatic brain injury. Rehabil Psychol. 2008;53(4):486-97.

18. Triebel KL, Martin RC, Nabors LB, Marson DC. Medical decisionmaking capacity in patients with malignant glioma. Neurology. 2009;73(24):2086-92.

19. Marson DC. Loss of competency in Alzheimer's disease: conceptual and psychometric approaches. Int J Law Psychiatry. 2001;24(2-3):267-83.

20. Palmer BW, Harmell AL. Assessment of healthcare decisionmaking capacity. Arch Clin Neuropsychol. 2016;31(6):530-40.

21. Sullivan K. Neuropsychological assessment of mental capacity. Neuropschol Rev. 2004;14:131-42.

22. Pachet A, Astner K, Brown L. Clinical utility of the mini-mental status examination when assessing decision-making capacity. J Geriatr Psychiatry Neurol. 2009;23(1):3-9.

23. Kim SY, Caine ED. Utility and limits of the mini mental state examination in evaluating consent capacity in Alzheimer's disease. Psychiatr Serv. 2002;53(10):1322-4.

24. Robson GA, Biggs V, Walker DG. Cognitive screening in brain tumors: short but sensitive enough? Front Oncol. 2015;5(60).

25. Pendlebury ST, Cuthbertson FC, Welch SJ, Mehta Z, Rothwell PM. Underestimation of cognitive impairment by Mini-Mental State Examination versus the Montreal Cognitive Assessment in patients with transient ischemic attack and stroke: a population-based study. Stroke. 2010;41(6):1290-3.

26. Kaufman DM, Geyer HL, Milstein MJ. Dementia. In: Kaufman DM, Geyer HL, Milstein MJ, editors. Kaufman's clinical neurology for psychiatrists (eighth edition): Elsevier; 2017. p. 105-49.

27. Coutlee CG, Huettel SA. The functional neuroanatomy of decision making: prefrontal control of thought and action. Brain Res. 2012;1428:3-12.

28. Mandarelli G, Parmigiani G, Tarsitani L, Frati P, Biondi M, Ferracuti S. The relationship between executive functions and capacity to consent to treatment in acute psychiatric hospitalization. J Empir Res Hum Res Ethics. 2007;7(5):63-70.

29. Kerrigan S, Erridge S, Liaquat I, Graham C, Grant R. Mental incapacity in patients undergoing neuro-oncologic treatment: a crosssectional study. Neurology. 2014;83:537-41.

30. Marson DC, Martin RC, Triebel KL, Nabors LB. Capacity to consent to research participation in adults with malignant glioma. J Clin Oncol. 2010;28(24):3844-50.

31.• Gerstenecker A, Meneses K, Duff K, Fiveash JB, Marson DC, Triebel KL. Cognitive predictors of understanding treatment decisions in patients with newly diagnosed brain metastasis. Cancer. 2015;121(12):2013-9. The first of a pair of papers reported by Gerstenecker et al. to investigate associations between cognitive performance and capacity in metastatic brain tumour patients. The understanding facet of CCTI capacity assessment was associated with a range of cognitive performances. Namely, phonemic fluency and verbal memory were found to be predictors of capacity to understand a treatment decision.

32.• Gerstenecker A, Duff K, Meneses K, Fiveash JB, Nabors LB, Triebel KL. Cognitive predictors of reasoning through treatment decisions in patients with newly diagnosed brain metastases. J Int Neuropsychol Soc. 2015;21(6):412-8. The second of the duo of case-controlled studies reported by Gerstenecker et al. 
Metastatic brain tumour patients' understanding of treatment decisions was found significantly associated with episodic memory and processing speed, allowing predictive equations for incapacity.

33. Triebel KL, Gerstenecker A, Meneses K, Fiveash JB, Meyers CA, Cutter G, et al. Capacity of patients with brain metastases to make treatment decisions. Psycho-Oncology. 2015;24(11):1448-55. A case-control study reporting around $60 \%$ of all patients diagnosed with brain metastases to show some form of deficit in capacity $(<1.5$ SD below the mean in one construct area) when assessed within a week of starting radiotherapy for their brain metastases.

34. Applebaum P, Grisso T. Assessing patients' capacities to consent to treatment. N Engl J Med. 1998;319:1635-8.

35. Okonkwo O, Griffith HR, Belue K, Lanza S, Zamrini EY, Harrell LE, et al. Medical decision-making capacity in patients with mild cognitive impairment. Neurology. 2007;69:1528-35.

36. Gempt J, Lange N, Bette S, Foreman SC, Cammardella JH, Albertshauser J, et al. Factors influencing neurocognitive function in patients with neuroepithelial tumors. Sci Rep. 2017;7(1):17764.

37. Fang S, Wang Y, Jiang T. The influence of frontal lobe tumors and surgical treatment on advanced cognitive functions. World Neurosurg. 2016;91:340-6.

38. Mattavelli G, Casarotti A, Forgiarini M, Riva M, Bello L, Papagno C. Decision-making abilities in patients with frontal low-grade glioma. J Neuro-Oncol. 2012;110:59-67.

39. Palmer BW, Savla GN. The association of specific neuropsychological deficits with capacity to consent to research or treatment. J Int Neuropsychol Soc. 2007;13:1047-59.

40. Mayo AM, Wallhagen MI. Considerations of informed consent and decision-making competence in older adults with cognitive impairment. Res Gerontol Nurs. 2009;2(2):103-11.

41. Noll KR, Sullaway C, Ziu M, Weinberg JS, Wefel JS. Relationships between tumor grade and neurocognitive functioning in patients with glioma of the left-temporal lobe prior to surgical resection. Neuro-Oncology. 2015;17(4):580-7.

42. Klein M. Lesion momentum as an explanation for preoperative neurocognitive function in patients with malignant glioma. Neuro Onco. 2016;18:1595-6.

43. Desmurget M, Bonnetblan F, Duffau H. Contrasting acute and slow-growing lesions: a door to brain plasticity. Brain. 2007;130: 898-914.

44. Seigers R, Fardell JE. Neurobiological basis of chemotherapy induced cognitive impairment: a review of rodent research. Neurosci Biobehav Rev. 2011;35(3):729-41.

45. Brown PD, Jaeckle K, Ballman KV, Farace E, Cerhan JH, Anderson SK, et al. Effect of radiosurgery alone vs radiosurgery with whole brain radiation therapy on cognitive function in patients with 1 to 3 brain metastases: a randomized clinical trial. JAMA. 2016;316(4):401-9.

46. Habets EJJ, Dirven L, Wiggenraad RG, Verbeek-de Kanter A, Lycklama à Nijeholt GJ, Zwinkels $\mathrm{H}$, et al. Neurocognitive functioning and health-related quality of life in patients treated with stereotactic radiotherapy for brain metastases: a prospective study. Neuro-Oncology. 2016;18(3):435-44.

47. Schimmel WCM, Verhaak E, Hanssens PEJ, Gehring K, Sitskoorn MM. A randomised trial to compare cognitive outcome after gamma knife radiosurgery versus whole brain radiation therapy in patients with multiple brain metastases: research protocol CAR-study B. BMC Cancer. 2018;18:218.

48. Gondi V, Tolakanahalli R, Mehta MP, Tewatia D, Rowley H, Kuo JS, et al. Hippocampal-sparing whole-brain radiotherapy: a "how- to" technique using helical tomotherapy and linear acceleratorbased intensity-modulated radiotherapy. Int J Radiat Oncol Biol Phys. 2010;78(4):1244-52.

49. Daniela Falco M, Giancaterino S, D'Andrea M, Gimenez De Lorenzo R, Trignani M, Caravatta L, et al. Hippocampal sparing approach in fractionated stereotactic brain VMAT radio therapy: a retrospective feasibility analysis. J Appl Clin Med Phys. 2018;19(1):86-93.

50. Gondi V, Pugh S, Brown PD, Wefel J, Gilbert M, Bovi J, et al. NCOG-01. Preservation of neurocognitive function (NCF) with hippocampal avoidance during whole-brain radiation therapy (WBRT) for brain metastases: preliminary results of phase III trial NRG ONCOLOGY CC001. Neuro-Oncology. 2018;20(6):vi172. https://doi.org/10.1093/neuonc/noy148.716.

51. Ryken TC, McDermott M, Robinson PD, Ammirati M, Andrews DW, Asher AL, et al. The role of steroids in the management of brain metastases: a systematic review and evidence-based clinical practice guideline. J Neuro-Oncol. 2010;96(1):103-14.

52. Dietrich J, Rao K, Pastorino S, Kesari S. Corticosteroids in brain cancer patients: benefits and pitfalls. Expert Rev Clin Pharmacol. 2011;4(2):233-42.

53. Eddy CM, Rickards HE, Cavanna AE. The cognitive impact of antiepileptic drugs. Ther Adv Neurol Disord. 2011;4(6):385-407.

54. Evers PD, Logan JE, Sills V, Chin AI. Karnofsky Performance Status predicts overall survival, cancer-specific survival, and progression-free survival following radical cystectomy for urothelial carcinoma. World J Urol. 2014;32(2):385-91.

55. Martin RC, Gerstenecker A, Nabors LB, Marson DC, Triebel KL. Impairment of medical decisional capacity in relation to Karnofsky Performance Status in adults with malignant brain tumor. Neurooncol Pract. 2014;2(1):13-9.

56. Loewenstein G, Lerner JS. The role of affect in decision making. In: Handbook of affective sciences; 2003. p. 619-42.

57. Campanella F, Shallice T, Ius T, Fabbro F, Skrap M. Impact of brain tumour location on emotion and personality: a voxel-based lesionsymptom mapping study on mentalisation processes. Brain. 2014;137:2532-45.

58. Zigmond AS, Snaith RP. The Hospital Anxiety and Depression Scale. Acta Psychiatr Scand. 1983;67:361-70.

59. Hindmarch T, Hotopf M, Owen GS. Depression and decisionmaking capacity for treatment or research: a systematic review. BMC Med Ethics. 2013;14(54).

60. Diaz JL, Barreto P, Gallego JM, Barbero J, Bayés R, Barcia JA. Proper information during the surgical decision-making process lowers anxiety of patients with high-grade glioma. Acta Neurochir. 2009;151:357-62.

61. Rozmovits L, Khu KJ, Osman S, Gentili F, Guha A, Bernstein M. Information gaps for patients requiring craniotomy for benign brain lesion: a qualitative study. J Neuro-Oncol. 2010;96:241-7.

62. Cote DJ, Balak N, Brennum J, Holsgrove DT, Kitchen N, Kolenda $\mathrm{H}$, et al. Ethical difficulties in the innovative surgical treatment of patients with recurrent glioblastoma multiforme. J Neurosurg. 2017;126:2045-50.

63. Ibrahim GM, Chung C, Bernstein M. Competing for patients: an ethical framework for recruiting patients with brain tumors into clinical trials. J Neuro-Oncol. 2011;104:623-7.

64. Bernstein M. Payment of research subjects involved in clinical trials is unethical. J Neuro-Oncol. 2003;63:223-4.

Publisher's Note Springer Nature remains neutral with regard to jurisdictional claims in published maps and institutional affiliations. 